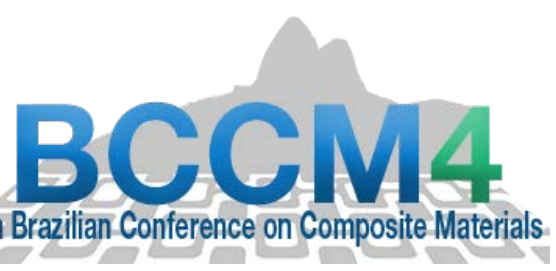

\title{
EFFECT OF GAMMA-RADIATION ON THERMAL AGEING OF BUTYL RUBBER COMPOUNDS
}

\author{
Sandra R. Scagliusi' ${ }^{1}$, Elizabeth C. L. Cardoso $^{1}$ and Ademar B. Lugão ${ }^{1}$ \\ (1) Instituto de Pesquisas Energéticas e Nucleares - IPEN-CNEN-SP - Av. Lineu Prestes \\ 2242 - CEP 05508-900 - Cidade Universitária, São Paulo, Brasil.
}

https://doi.org/10.21452/bccm4.2018.04.03

\begin{abstract}
Butyl rubber has a comprehensive use in sealing systems, especially in tires inner tubes, due to their low permeability to gases. So, it is required that butyl rubber compounds show a better performance, more and more. Butyl rubber is provided with excellent mechanical properties and oxidation resistance. Besides showing these properties, radiation exposures impart modifications in physical-chemical and morphological properties on butyl rubber materials. When exposed to gamma-radiation, rubbers suffer changes in their mechanical and physical properties, caused by material degradation. The major radiation effect in butyl rubbers is chain- scission; besides, ageing promotes too the same effect with further build-up of free radicals. This work aims to the study of gamma-radiation in physical-chemical properties of butyl rubber subjected to thermal ageing. Doses used herein were: $25 \mathrm{kGy}, 50$ kGy, 100 kGy, 150 kGy and 200 KGy. Samples were evaluated before and after ageing according to traditional essays, such as: hardness, tensile strength and elongation at break. From accomplished assessments it is possible to affirm that at doses higher than $50 \mathrm{kGy}$ it was observed a sharp decreasing in butyl rubber physical-chemical properties, before and after exposure to ageing.
\end{abstract}

\section{INTRODUCTION}

Ageing effect study in rubber artifacts is relevant especially due to cost and quality, providing to the material resistance or not to exposure under more severe environmental conditions. Ageing degree depends on various factors as polymer type, formulation, product geometry and environmental conditions [1].

Accelerated ageing essays aim to reproduce within a relatively shorter time interval ageing effects due to air action, radiation and temperature from larger exposures. For this, an adequate combination is accomplished between exposure periods and temperatures. Thermal ageing in rubber compounds present their physical and mechanical properties changed in function of modifications in structure or in morphology. 
Ageing expression for rubber compositions is related to molecular scission that provokes the appearing of smaller chains and a higher number of chain terminals and/or crosslinking favoring a network structure strongly connected [2].

Both of two basic reactions yield to elastomer chemical structure changes and are able to be exemplified according to mechanism shown in Figure 1, for simplified radical [3].Free radicals can be built up by decomposition of small amounts of hydro-peroxides, present in rubber after the processing. Depending on rubber type, these reactions lead to either a chainscission or to a raise in crossing bonds [4].

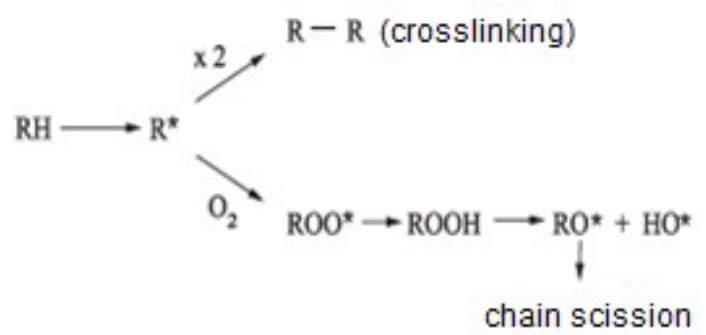

Figure 1: Elastomers reaction mechanism after ageing

It should be considered that chain-scission provokes a decreasing in viscosity, but, in case of crosslinking, the material becomes more rigid. Combination between scission and crosslinking results in creation of micro-cracks; presence of oxygenated products was detected even before the occurrence of chain-scission [3].

Butyl rubber is an isobutylene copolymer (98\%) and isoprene (2\%). In its hydrocarbon chain, unsaturation level is very low fostering an excellent resistance to ageing [5]. Butyl rubber when subjected to ionizing radiation exhibits two chemical effects: crosslinking and chain-scission with further degradation; nevertheless, chain-scission is predominant [6]. Various authors concluded that the major and practically unique effect due to ionizing radiations in butyl rubber is chain-scission with a significant reduction in molar mass, prejudicing physical and mechanical properties of the rubber. [7].

Rubber ageing is a structural chemical phenomenon that affects directly material mechanical properties. Thermo-oxidative ageing and radiation modify compound molecular structure imparting changes in rubber properties. According to Farmer [8] and collaborators, oxidation in polymers occurs with settlement of molecular oxygen in double bond to yield oxidized peroxide.

This work aims to the study of accelerated ageing in vulcanize compositions of butyl rubber before and after gamma-radiation, within 0 to $200 \mathrm{kGy}$. Behavior of studied materials for different doses applied was assessed as per mechanical properties.

\section{MATERIALS}

The elastomer used in this study was butyl rubber manufactured by Exxon Mobil Chemical, butyl 268 as commercial name, zinc oxide, stearic acid, sulphur, 2,2dithiocarbaptobenzotiazol (MBTS) and tetrametiltiuram disulfide (TMTD), all of them commercial grade and used as such. Compositions were prepared according to a formulation normally used in tires and auto-parts industry (Table 1). Referred composition was irradiated and further subjected to accelerated ageing process. 
Table 1. Formulation of Butyl Rubber.

\begin{tabular}{ll}
\hline Ingredients & Quantities (phr) \\
\hline Butyl rubber & 100 \\
Zinc oxide & 5 \\
Stearic acid & 1 \\
Naphthenic oil & 25 \\
Carbon black N 330 & 70 \\
Sulfur & 2 \\
TMTD & 1 \\
MBTS & 0.5 \\
\hline
\end{tabular}

\subsection{Mixture and vulcanization process}

Samples were prepared in an open cylinder (Copê), with two rolls, $40 \mathrm{~kg}$ capacity, according to ASTM D-3182 [9], at approximately $60{ }^{\circ} \mathrm{C}$; just after, the compound was vulcanized in a HIDRAUL-MAQ hydraulic press,5 MPa pressure and prepared according to ASTM D-3182 [9], at $180{ }^{\circ} \mathrm{C}$, for 4 min, packed in plastic bags and sent to irradiation.

\subsection{Ageing}

Butyl rubber composition after irradiation was subjected to accelerated ageing in an airforced oven, at $70{ }^{\circ} \mathrm{C}$, for $72 \mathrm{~h}$, in accordance with ASTM D 573 [10]. Aged mixtures were assessed for tensile strength, elongation at break and hardness. Specimens thickness used in ageing essays were: $0.6 \mathrm{~cm}$ for hardness and $0.2 \mathrm{~cm}$ for other tests.

\subsection{Irradiation}

Samples were irradiated in CBE/EMBRARAD and subjected to gamma radiation, in oxygen environment, at 25, 50, 100, 150 and 200 kGy doses, in Nordion Canadian irradiator, Cobalt 60 source, Model JS 7500, $5 \mathrm{kGy} \mathrm{h}^{-1}$ dose ratio.

\section{METHODS}

\subsection{Compounding Characterization}

Analyses were accomplished according with ASTM rules, in triplicate, for obtaining results average. Specimens were cut in accordance with specified methods of each essay. There were performed following tests:

\subsection{Hardness}

Hardness numerical indexes represent the deepness of penetration or adequate arbitrary values, derived from ASTM D 2240 [11]. Hardness is one of the properties the most evaluated in rubbers, being the Shore A, Instrutemp, portable digital model Dp-100 the durometer used herein. This instrument is provided with a conical needle emerging from the apparatus, kept at zero level by means of a spring.

\subsection{Tensile strength and elongation at break}

Tensile strength and elongation at break values were determined according to ASTM D412 [12], by using a model C specimen, in an universal essay machine (EMIC), model DL 300, $300 \mathrm{kN}$ maximum capacity and $500 \mathrm{~mm} / \mathrm{min}$ grips speed, at room temperature. 


\section{RESULTS AND DISCUSSION}

In Figure 2 (a e b) are shown results for Tensile Strength (a) and results for Elongation at Break (b) accomplished in butyl rubber irradiated and non-irradiated, before and after thermal ageing.

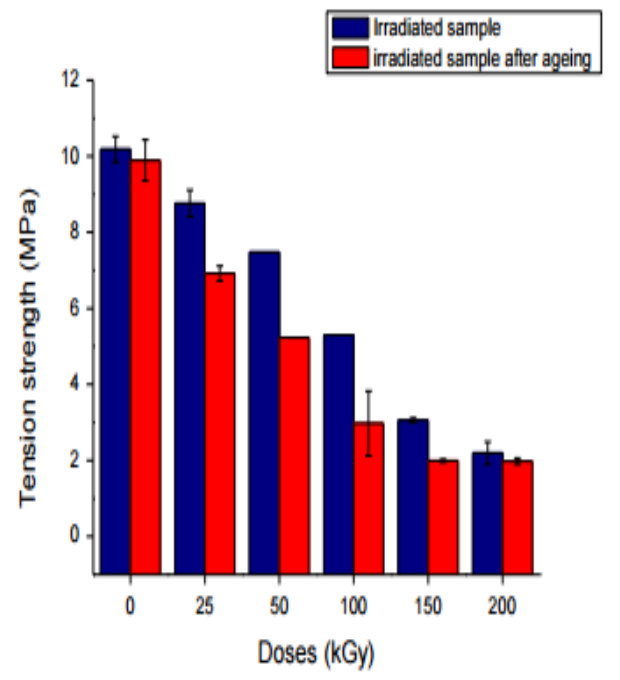

Figure 2 (a) -Ageing effect in strengthin in butyl rubber compounds, irradiated and non irradiated, subject to ageing

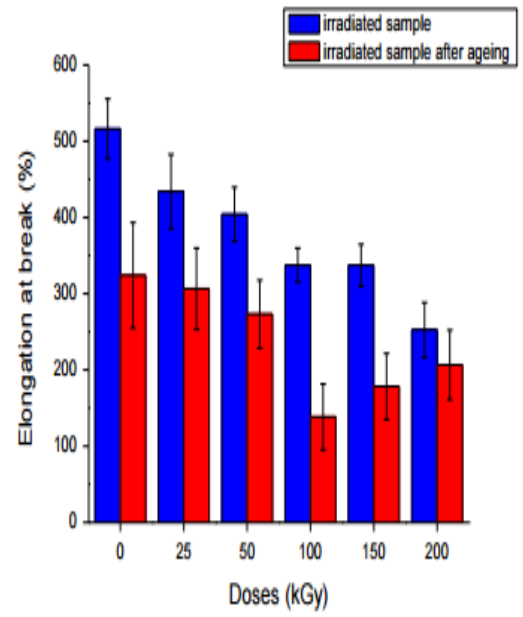

Figure 2 (b) -Ageing effect in elongation at break in butyl rubber compounds, irradiated and non irradiated, subject to ageing .

Tensile strength and elongation at break results for butyl rubber samples showed that for low doses up to $25 \mathrm{kGy}$ there is equivalence among tensile and elongation values after ageing, pointing that degradative effects were not enough to change these properties. For doses within $25 \mathrm{kGy}$ and $50 \mathrm{kGy}$ it is observed a decreasing in tensile and a balance in elongation results, probably due to a competition between scission and crosslinking, with number of crosslinking compensating chain scission. For doses within $100 \mathrm{kGy}$ and $200 \mathrm{kGy}$ it was observed a predominance of chain scission: smaller molecular chains have weaker intermolecular forces that do not resist to tensile strength.

Hardness is directly associated to rubber crosslinking degree: the more vulcanized the higher compound hardness. In Figure 3 are shown results for accelerated ageing of irradiated butyl rubber samples.

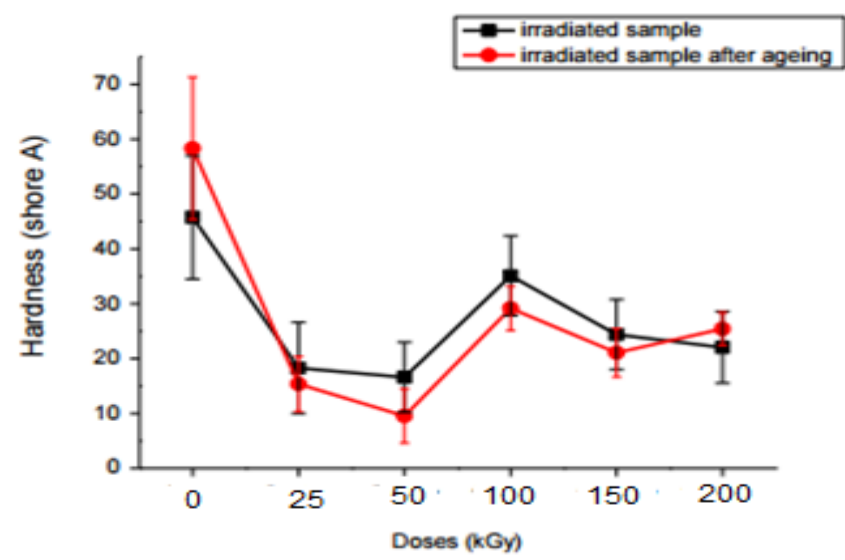


Figure 3: - Effect of ageing in hardness of butyl rubber compounds, irradiated and nonirradiated subjected to ageing.

According previously explained, hardness increases in function of a raise in crossing bonds [13]. Results showed that for non-irradiated sample (0 kGy) occurs an increase in hardness after ageing pointing toward a raise in build-up of crossing bonds imparting a higher stability to the compound. After irradiation and thermal ageing the hardness diminishes with further reduction in density of crossing bonds. For higher doses (above $50 \mathrm{kGy}$ ) occurs a slight raise without proportionality to dose, probably caused by oxidative degradation of polymeric chain.

The results of accelerated aging tests on butyl rubber compounds showed that the initial composition, even after irradiation, has a lower crosslinking index, therefore it will be possible to make blends with $25 \mathrm{kGy}$ irradiated butyl rubber compositions after aging. . In future work, a mixture of 5 parts of aged butyl rubber will be performed replacing virgin butyl rubber parts in the original formulation that was used in this work, as shown in table 2.

Table 2. Formulation of Butyl Rubber.

\begin{tabular}{cc}
\hline Ingredients & Quantities (phr) \\
\hline Butyl rubber & 95 \\
Ageing butyl rubber & 5 \\
Zinc oxide & 5 \\
Stearic acid & 1 \\
Naphthenic oil & 25 \\
Carbon black N 330 & 70 \\
Sulfur & 2 \\
TMTD & 1 \\
MBTS & 0.5 \\
\hline
\end{tabular}

\section{CONCLUSIONS}

Processing using gamma rays in butyl rubbers proved a tendency toward chain scission with further free radicals build-up. Obtained results showed that gamma rays processing followed by thermal ageing caused a higher degradation in this type of rubber. Tensile strength tests showed gel build-up and consequently a more rigid and less elastic rubber.

Based in given results it can be concluded that aged butyl rubber compounds show a higher crosslinking density and exhibit a higher vulcanization degree when compared to nonirradiated compound, and consequently, best properties. Gamma rays are a powerful degradation agent for rubbers; together with thermal agent imparts to rubber a low crosslinking density even at low doses. Increasing of the dose imparts chain scission with molar mass reduction with further degradation and a few crosslinking sites.

It can be concluded that the aging mechanisms in the butyl rubber may also be acting to weaken the elastomeric matrix due to a main chain scission that contributes to the reduction of the analyzed properties, which allows its mixture in butyl rubber compounds, replacing parts of virgin butyl rubber for recycling purposes.

\section{ACKNOWLEDGMENTS}

The authors wish to thank CBE Embrarad for the irradiation process, Pirelli for the elastomers, Basile Chemistry for the raw materials, IPEN/CNEN-SP and CAPES agencies for their financial support. 


\section{REFERENCES}

[1] R. P. Brown, M. J. Forrest, G. Soulagnet, - Rapra, 10, 3, 1999.

[2] M.Garbarczyk, W. Kuhn, J. Klinowski, S. Jurga, "Characterization of aged nitrile rubber elastomers by NMR spectroscopy and microimaging”. Polymer, 43, (2002), 3169-3172.

[3] P. Lucas, M. Baba, J. Lacoste, J. L. Gardette, "Crosslinking of dienic elastomers resulting from ageing: X-ray diffraction and refractometry measurements”.Polym. Degr. Stab.,76, (2002), $449-453$.

[4] E. Somers, T. J. Bastow, M. I. Burgar, M. Forsyth, A. J.Hill, “Quantifying rubber degradation using NMR” - Polym. Degr. Stab., 70, (2000) 31 -37.

[5] M. J. Caetano, Borracha Butílica: Poliisobitileno isopreno (IIR). http://ctborracha.com/?page_id=4330.

[6] A.Chapiro, Radiation Chemistry of Polymeric Systems, Nova York: (Interscience Publishier, 1962).

[7] T. Zaharescu, C. Postolache, M. Giurginca, "The structural changes in butyl and halogenated butyl elastomers during gamma irradiation”, J. of Appl.Polym.Sci.,59 (1996) 969- 974.

[8] E. H. Farmer, H. P. Koch, D. A. Sutton, "The Course of Autoxidation Reactions in Polyisoprenes and Allied Compounds. VII. Rearrangement of Double Bonds During Autoxidation”. J. Chem. Soc.,3 (1943) 541-547.

[9] Annual Book of Astm Standards. Standard Practice for Rubber- Materials, Equipment, and Procedures for Mixing Standart Compounds and Preparing Standard Vulcanized Sheets .v. 09.01, 2008 (ASTM D-3182).

[10] Annual Book of Astm Standards. Standard Test Method for Rubber - Deterioration in Air Oven, v. 09.01, 1996 (ASTM D-573).

[11] Annual Book of Astm Standards. Standard Test Method for Rubber Property - Durometer Hardness. v. 09.01, 2008 (ASTM D-2240).

[12] Annual Book of Astm Standards.Standard Test Methods for Vulcanized Rubber and Thermoplastic Rubber and Thermoplastic Elastomers - Tension.v. 09.01, 2008 (ASTM D412).

[13] R. JOSEPH, K. E. GEORGE, D. J. FRANCIS, "Studies on the cure characteristics and vulcanizate properties of 50/50 NR/SBR blend”. J. Appl. Polym. Sci., 35 (1988) 1003-1017. 